\title{
Proposal for a New Entertainment System That Connects Real Life and Net Excitement
}

\author{
Kazuma Hidaka ${ }^{1}$ and Katsuhiko Ogawa ${ }^{2}$ \\ ${ }^{1}$ Graduate School of Media and Governance Keio University, Fujisawa, Kanagawa, Japan \\ ${ }^{2}$ Faculty of Environment and Information Studies Keio University, Fujisawa, Kanagawa, Japan \\ \{khidaka, ogw\} asfc.keio.ac.jp
}

\begin{abstract}
This paper describes a new entertainment system that enables sharing the experiences of concert halls audiences on the Web with the use of a penlight and Smartphone application. This system captures the audience's excitement and mood during a concert and then uses that data to annotate a video of the concert. Other users can relate to the audience experience in synch to the video. This system consists of a LED light stick attached to a Smartphone waved by the audience and annotates with emoticons timestamped on each particular moment. Further, the test to extract problems of usability of this system and the brief test to evaluate the user experiment of the whole system was carried out. By these test, it was suggested that this system could make a positive change to the experience of the concert.
\end{abstract}

Keywords: Annotation System, Penlight, Smartphone Application, Entertainment System.

\section{Introduction and Background}

At a concert hall, the audience shows their excitement by shaking a penlight following the music rhythm. A common penlight is a very simple device with the shape and size of a pen that emits a glowing color light. It is a very important tool for demonstrating that the audience is enjoying the music concert. However, this is an experience that is possible just on the spot and done by the audience only there, and sharing with others after the concert is difficult, and soon forgotten.

On the other hand, when watching the show on the net (such as Ustream and niconico douga [1], for example), the audience represents their excitement by adding comments on the video of the concert [2]. However, the result of the excitement that generates the show is completed only on the net, it is not tied to the experience lived in real life.

In this way, the excitement of a concert enjoyed in real life by using a penlight and the excitement of the same concert on the net shown by the comments, are isolated; and the media that fuse that excitement of real and net emotions does not exist so far.

In this paper, the system to share on the net the impression generated in the real world is built. This is made by developing an application that can be used to record the excitement in the concert hall, allowing the system to automatically add that annotation data into the concert video. The storyboard [3] of this system is shown in Fig.1. 


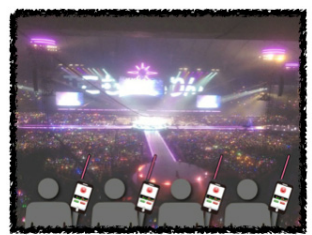

I. Users attaching the device and watching a concert

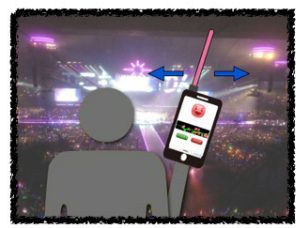

2. Shaking the device and enjoying a concert

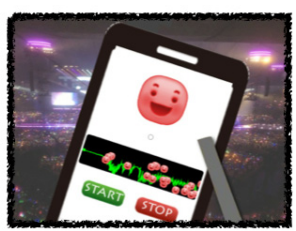

3. Touching the icons displayed on the screen

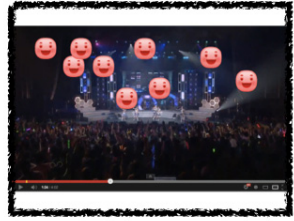

4.After the concert, watching the concert video

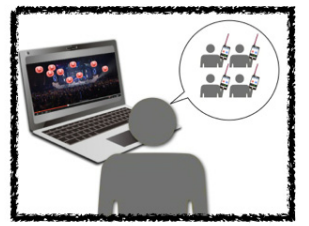

5. The video with the icons the other users touched

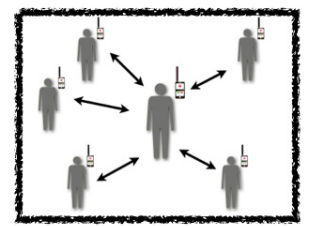

6. Using this system, people can share on the net the impression generated in real world

Fig. 1. Storyboard of this System

The test to extract the user's requirement, the problem of GUI design Smartphone application, and the problem of the user interface of the entire system was carried out in the Karaoke box imitating real concerts. And the brief test to evaluate the user experience of the whole system was carried out.

\section{Penlight Annotation on the Screen System}

The purpose of this study is building a new entertainment system that share real excitement on the net by using a penlight and Smartphone application. Users use the system according to the procedure described as it follows: First, users attach our penlight device to the Smartphone, and start the application. During the concert, users touch the emoticons displayed on the screen to demonstrate whether they feel excited, bored, impressed, etc. After the concert, users watch the video and see in parallel which emoticons the audience touched, and evoke how they were feeling back then when attending the show, minute by minute. This system flow diagram is shown in Fig.2.

\section{Implementation}

In order to implement this system, three fundamental parts were developed.

- Penlight device

- Smartphone application

- Video annotation system 


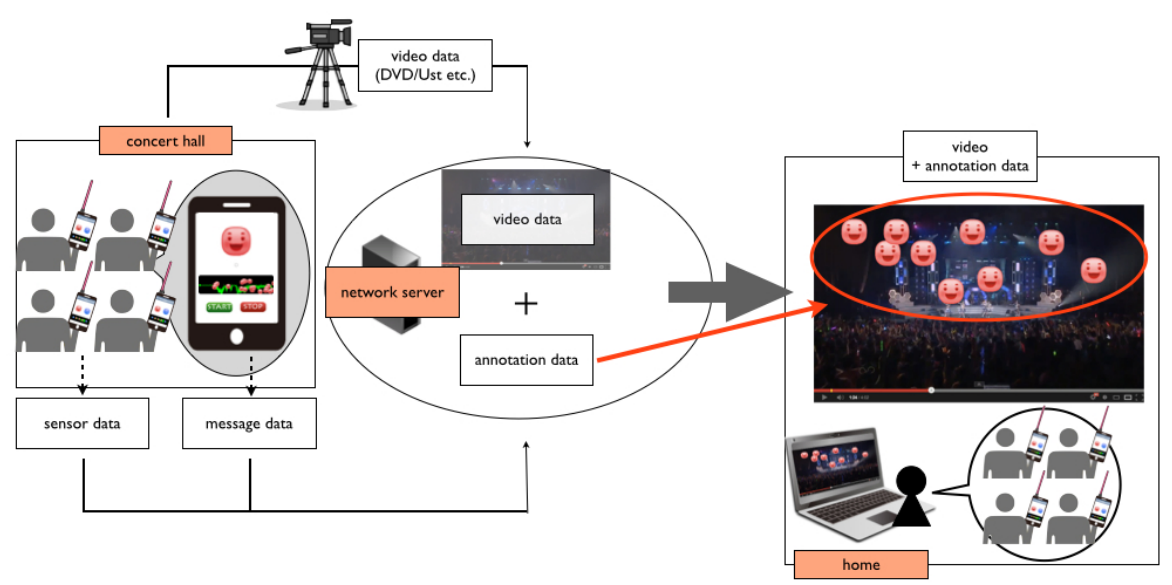

Fig. 2. System Flow Diagram

\subsection{Penlight Device}

Users use this system by attaching the penlight device to the Smartphone. This device, in order to omit the battery of the external device is supplied power from the headphone jack of the Smartphone. The headphone jack of the iPhone has a 2-channel $\mathrm{L} / \mathrm{R}$. The impedance of the output from each terminal is $36 \Omega$, and maximum output voltage is $0.95 \mathrm{Vrms}(2.7 \mathrm{~V}$ peak-to-peak). It is a low voltage as it is. It is possible to turn on the LED by going through the chopper type booster circuit (Fig.3).

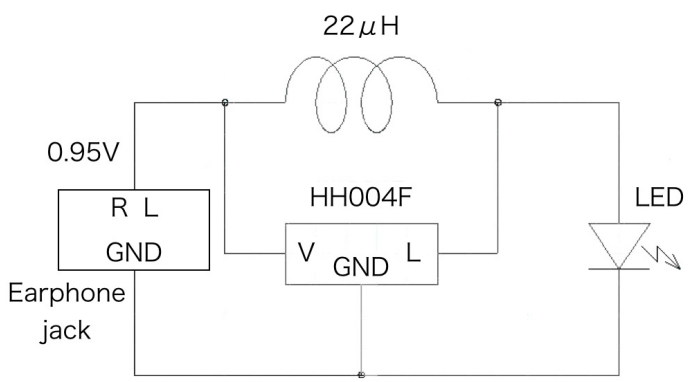

Fig. 3. Circuit Diagram of the Penlight Device

The device outputs square wave signal of frequency $440 \mathrm{~Hz}$ from the $\mathrm{L} / \mathrm{R}$ channel at the same time launch the application, and starts lighting of the LED. 


\subsection{Smartphone Application}

In this system, this application is implemented using the iPhone terminal. This application saves three different kind of information:

- The emoticon data touched by the users

- The acceleration sensor data

- The time stamp data

Users can express the impressions of the concert in real time easily by touching the emoticon displayed on the application. The application screen recording data is shown in Fig.4. In addition, it is possible to determine when users were shaking the device by recording the acceleration sensor data. By using this, we can obtain a barometer of the excitement during concert. These data that users get offline will be collected, and transmitted to the server after the concert. This application is getting the time stamp data every 0.1 second. Later, the video and the annotation data are synchronized by the time stamp information.

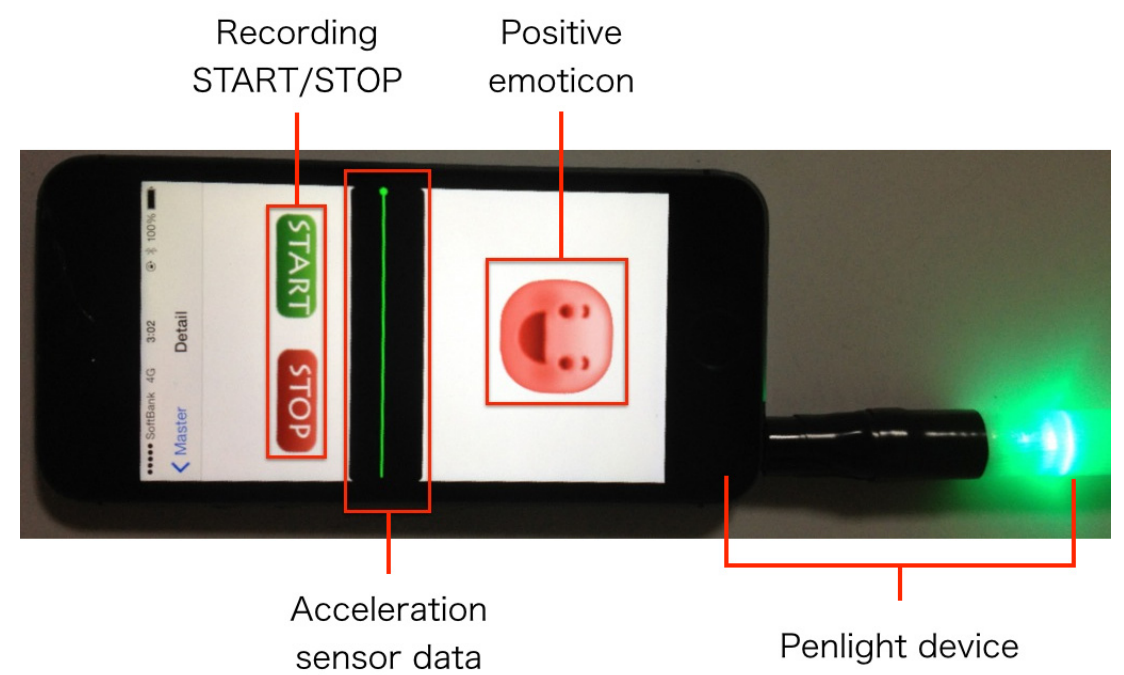

Fig. 4. The Application Screen and the Penlight Device

\subsection{Video Annotation System}

In this system, the saved information is synchronized with the video. The annotation data match the video and flow all over the screen from right to left. Users can see how excited the users were just by viewing the annotation data users or others recorded.

The synchronization of the video and annotation data is performed by matching the time of each device recorded with the time the concert was recorded. That is, it is necessary that the time data recording starts be set with the concert video. Because 
iPhone has the ability to adjust to standard time automatically, it is possible to match the time stamp data with the time of video is recorded in the area employing the same standard time.

This system employs a Japan Standard Time (JST). The device side is based on the time stamp data of the start button is pressed. The video side is based on the time 30 minutes before the concert begins (Time like always includes the time that is assumed when the user presses the start button). First, the difference between the base time of the device and the movie is calculated. Then, after playing the video, wait for the time of the difference, this system will start the display of the stamp. Since the device gets the time stamp every 0.1 seconds, deviation of the time stamp of the video is in 0.1 seconds or less. In the manner described above, two data sources are synchronized.

\section{User Experiment and Evaluation}

In order to investigate the effectiveness of this system in venues imitating real concerts, we carried out a test to verify the experience of the smartphone application and LED penlight (hereinafter, test 1) and also a brief test to observe the annotated movie (hereinafter, test2).

The purpose of the test 1 was to extract the user's requirement, the problem of GUI design Smartphone application, and the problem of the user interface of the entire system. The purpose of test 2 is the impression evaluation of the annotated movie. The results obtained by these experiments, we will improve the system design to the next. Verification of the effectiveness of this system was carried out by the free expression answer questionnaire and semantic differential method. The results obtained by the user experience, improvements for the next system design can be obtained.

\subsection{Users}

Test 1 was conducted in January 2013 in a Karaoke Box in Kanagawa, Japan. The users for the test were four Japanese university students. (20-23 years of age, 21.8 years average age, 2 males and 2 females). During the test, some problems by actually experiencing the application could be discovered. In test 2 , we requested the same users to watch the annotated movie three days after the test1, and asked answer the impression they had of the annotated video.

\subsection{Method of Test1}

Steps of test1 are as follows: First, because this is a completely new entertainment system, we had a demonstration in order overview of the application, the concept and basic use. We explained how to change to stamp recording screen and how to operate the stamp-recording screen is performed, then the user has actually used. The stage of the karaoke box was assumed to be the hall of a concert, and the performer sang three songs (about 1 minute 30 seconds for each song). This was for reducing the possibility that the users know and like the songs and affect in the final result.

The songs that are registered in the karaoke were used. The first song was "God knows... / Haruhi Suzumiya", the second song was "We Are Never Ever Getting 
Back Together / Taylor Swift", the third song was "Hatsukoi cider / Buono!". The users went through the experience of arriving at the concert venue, installing the LED penlight, launching the application, participation in the concert and finish.

Then, a questionnaire survey on GUI was conducted. We asked them to answer the GUI checklist [4]. GUI checklist is a checklist made on the basis of three principles of screen visualization [5] and six principles of screen interface design [6].

Next, by having them talking about feeling and troubles for each screen, protocol analysis [7] was conducted. Users were divided into two groups of two.

Finally, usability task analysis [8] was conducted. We distributed the questionnaire was to organize the six tasks when using this system; users entered in five levels (1 5) good points, bad points, and evaluation points. Because it is not a user who is familiar to this system in the test of time, it adopted the sentence completion method (with whom to answer in a style "Because (A), (B) is (C).").
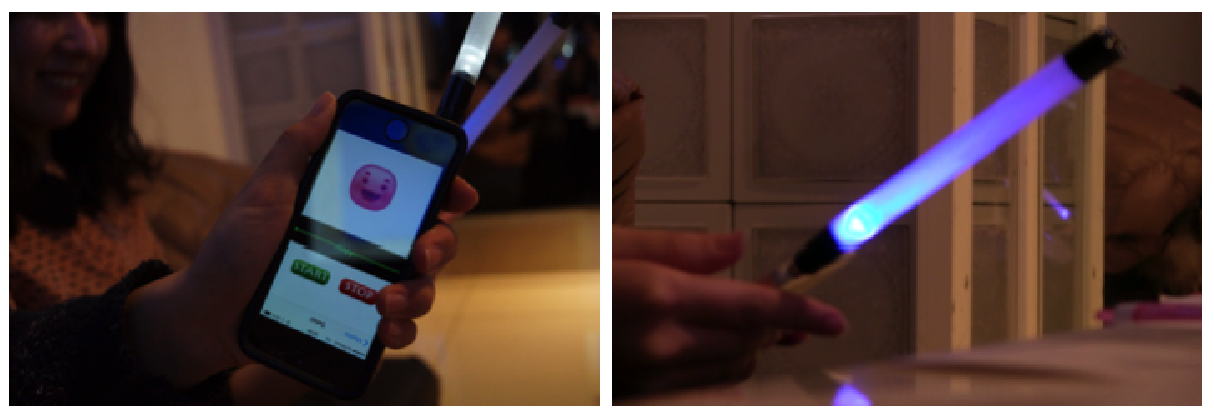

Fig. 5. Users Taking the Test1

\subsection{Method of Test2}

Test 2 was carried out 3 days after test 1 . We had edited the concert video that the performer sang in the test1, prepared two types. One is annotated movie; the other is not annotated movie. For each movie, the impression was evaluated by using 10 adjective pairs about affective value and arousal value [9]. The reason why movie 2 was also evaluated together is in order to obtain a change in score of between movie 1 and movie2 in consideration of shot cut rate, motion intensity, brightness, contrast, saturation, color energy, etc. of the movie material itself after editing.

Adjective group to be used for the impression evaluation experiment was extracted from five affective value and arousal value adjectives refer to the adjective group that is used in the Modified Mehrabian and Russell model [10]. In this experiment, adjectives that are commonly used in Japan were used. The environment for watching the movies was the laptop PC of each of them. After uploading to YouTube each movie, users viewed them in 1280*720pixel resolution. The capture video that was used is shown in Fig.6. They were divided into two groups of men and women 1; group1 viewed in the order of movie1, movie2, and group2 viewed in the order of viewing movie2, movie1. 4 users were used for this testing, and only the calculation of valance 
feature and arousal feature score was done Analysis of the correlation between the amounts of annotation is going to be performed in the future.

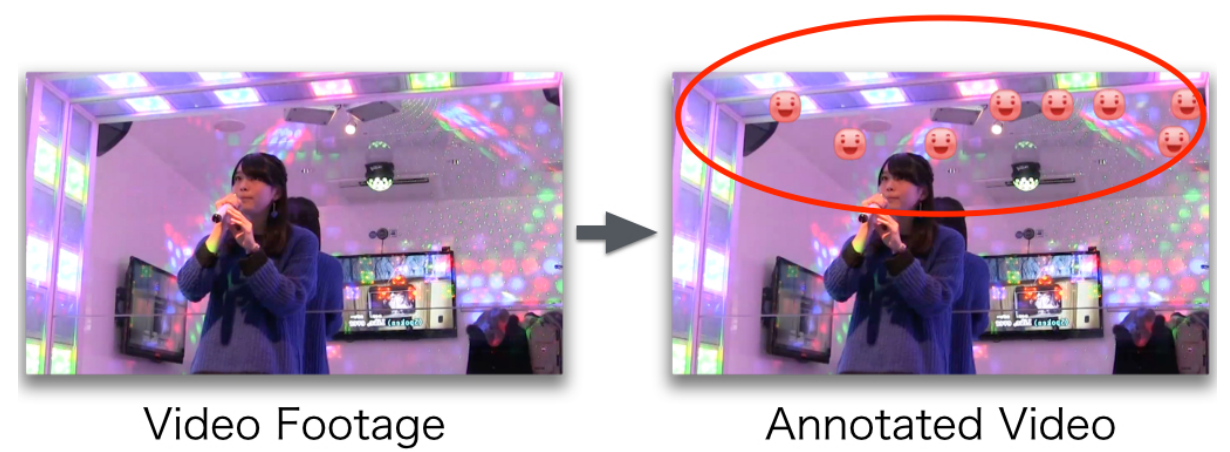

Fig. 6. Capture of Annotated Video that was used in the Test2

\section{Result and Discussion}

The problems found when the users tried to perform the tasks in the system came out after evaluating the usability task analysis and protocol analysis. The result is shown in Table 1. Answers were obtained by asking them talk freely about the good or bad points of this system and fill out a questionnaire of the sentence completion method

Table 1. The Result of Extraction of the Problems about each Task

\begin{tabular}{|c|c|c|c|}
\hline \multirow[b]{2}{*}{ Task } & \multicolumn{3}{|c|}{ Extraction of the problems } \\
\hline & Understanding and judgment & Operation & $\begin{array}{l}\text { Mean } \\
\text { score } \\
(\mathrm{SD})\end{array}$ \\
\hline Attaching a penlight & - & $\begin{array}{c}\text { When I shake, there is a sense of } \\
\text { anxiety that would break and come } \\
\text { off. }\end{array}$ & $3.3(1.3)$ \\
\hline Creating a concert & $\begin{array}{l}\text { If the user does not own the iPhone, } \\
\text { there is a possibility that hard to under- } \\
\text { stand the meaning of the button. }\end{array}$ & $\begin{array}{l}\text { I want to set the image or name of the } \\
\text { concert. }\end{array}$ & $3.8(1.0)$ \\
\hline $\begin{array}{l}\text { Changing to stamp } \\
\text { recordable state }\end{array}$ & $\begin{array}{l}\text { It is difficult to check the status because } \\
\text { the change on the display is small. }\end{array}$ & $\begin{array}{l}\text { Because of gender of the size of } \\
\text { users' hand, the easiness to press that } \\
\text { button is different. }\end{array}$ & $3.8(1.0)$ \\
\hline $\begin{array}{l}\text { Stamping a emoti- } \\
\text { con }\end{array}$ & - & $\begin{array}{l}\text { It is hard to push for a small emoti- } \\
\text { con. The size as can push without } \\
\text { looking at hand is good. }\end{array}$ & $3.3(1.0)$ \\
\hline $\begin{array}{l}\text { Recording accelera- } \\
\text { tion data }\end{array}$ & $\begin{array}{l}\text { During the concert. It was unlikely to } \\
\text { look at the screen. }\end{array}$ & - & $4.0(0.8)$ \\
\hline Exiting stamp record & $\begin{array}{l}\text { It is difficult to check the status because } \\
\text { the change on the display is small. }\end{array}$ & $\begin{array}{l}\text { Size of the hand because of the } \\
\text { different, such as by gender of the } \\
\text { user, easy to press that position is } \\
\text { different. }\end{array}$ & $3.8(0.5)$ \\
\hline $\begin{array}{l}\text { Comprehensive } \\
\text { evaluation }\end{array}$ & $\begin{array}{l}\text { By looking at the hand at the time of } \\
\text { operation, it is not possible to maintain- }\end{array}$ & $\begin{array}{l}\text { Etc. add record screen, start screen and } \\
\text { end screen, it is preferable to increase }\end{array}$ & $4.3(0.5)$ \\
\hline
\end{tabular}


\begin{tabular}{|l|l|l|l|}
\hline & ing immersive feeling. & the between screen transition. & L
\end{tabular}

about the task of the operation screen. Then, users filled out scores in five levels for each evaluation. The mean and standard deviation score and the problem for each task are shown in Table1.Scores are lower, in the "Attaching a penlight", "Stamping a emoticon" tasks. It is 3.25 both. We considered that the score of "Attaching a penlight" is low, because there were some users who could not attach the penlight unless they remove the cover cases that are placed on their Smartphone.

The result of GUI checklist is shown in Table 2. "Adequacy of navigations and routes for obtaining information", "Operation error tolerance", "Flexibility, customization" score was low. As described above, it is necessary to compensate for insufficiency of navigation by addition of the operation description and increase the navigation system. Further, because the back button to the previous screen is positioned at the bottom right of screen, there was an error that would push the button by mistaking at the base of the right hand when the user have a device with the right hand. The same "Flexibility, customization" also, it is necessary to design a system that allows the user to change the position and size of the button. It is possible to operate briefly and intuitively, and, because it does not require special operations, even unfamiliar users to this system had the possibility to earn how to operate easily.

Table 2. The result of GUI checklist

\begin{tabular}{|l|c|}
\hline Items & Mean scores (SD) \\
\hline Ease of understanding items & $3.8(1.3)$ \\
\hline Emphasis of important items & $3.3(1.5)$ \\
\hline Simplicity of information and layouts & $4.8(0.5)$ \\
\hline Adequacy of navigations and routes of obtaining information & $\mathbf{2 . 8 ( 1 . 3 )}$ \\
\hline Ease of understanding of terms & $3.0(0.8)$ \\
\hline Redundancy of information & $4.0(0.8)$ \\
\hline Adequacy of information mappings & $4.23(0.5)$ \\
\hline a visual or hearing feedback & $\mathbf{4 . 0}(0.8)$ \\
\hline Adequacy of operation time & $4.8(0.5)$ \\
\hline Confirmation of the time course of the operation & $3.3(1.5)$ \\
\hline Consistency of operation & $4.5(1.0)$ \\
\hline The explicitness of the hierarchical structure & $4.0(1.4)$ \\
\hline Consistency of interface and operation image for GUI & $3.8(1.0)$ \\
\hline Ease of understanding of the whole system & $3.8(1.3)$ \\
\hline Operation error tolerance & $\mathbf{2 . 3 ( 1 . 0 )}$ \\
\hline Flexibility, customization & $\mathbf{2 . 8 ( 1 . 0 )}$ \\
\hline
\end{tabular}

Image profiles obtained by test 2 are shown in Fig.7. The result shows a change in 
arousal feature is "Aroused-Unaroused". Because the amount of annotation is low, the comment that they feel rather lonely was obtained from the user who scored high on

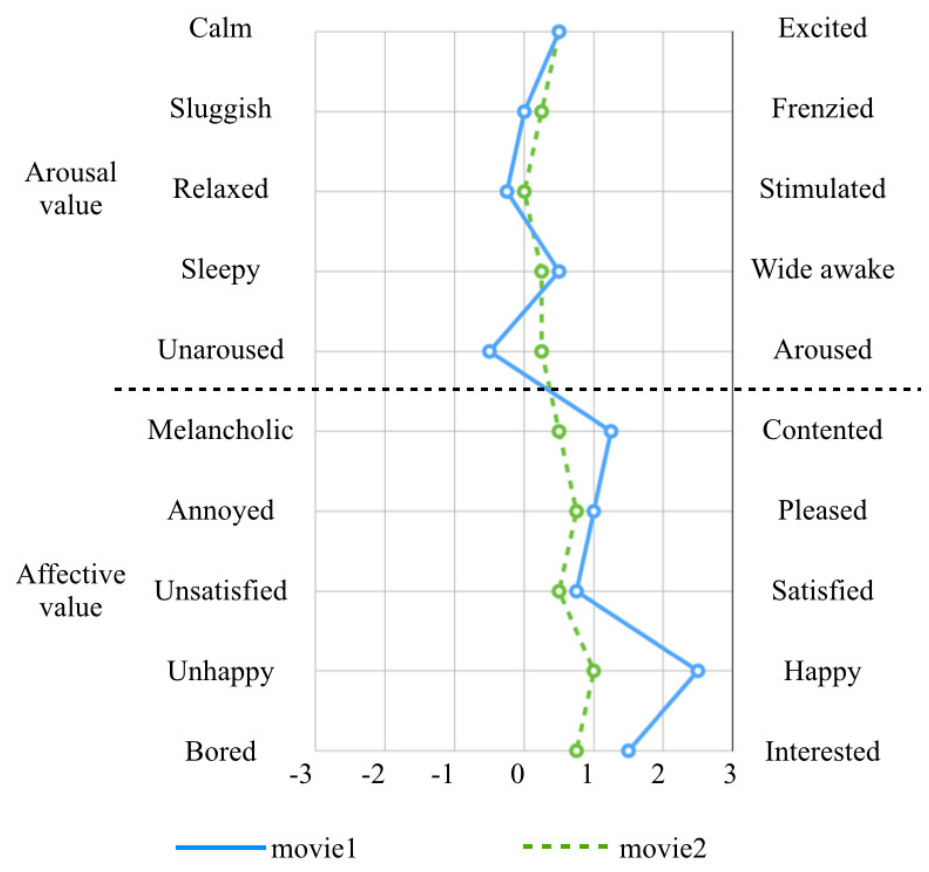

Fig. 7. Image Profiles Obtained by Test 2

the Unaroused. With respect of valance feature, positive changes were obtained in every item. For example, "I did not get tired because there were changes in the screen more movie1. It was interesting not only for the performers, but also to know the audience reaction", "Without knowing the song, it is convenient to be able to know when it becomes more lively. It is fun to share that excitement.", comments such as described above were obtained. This is considered that we were able to achieve the concept in this system.

However, the opinion that feels emoticon is a nuisance when the eyes of the performer are hidden by emoticon was obtained. On the other hand, conflicting comments of "It may feel exciting so emoticon should fill the screen" were obtained. The number of times the user who answered that emoticons was getting in the way is less (9.4 times / minute), the number of times the user who answered that emoticon should fill the screen pushed is very often (37.4 times / minute).

\section{Conclusion and Future Work}

This paper described how to build this system, and prototype testing. In the user test, it is suggested that this system can make a positive change to the experience of the concert. Addition, it is necessary to examine whether two-dimensional sensitivity 
model of affective value and arousal value can be applied. Moreover, by obtained the causal relationship between affective value-arousal value and the amount of the annotation, it is possible to derive the amount of the appropriate annotations.

The results of test 1 and test 2 , some problems in usability were found. It is necessary that it can be customized to suit the preferences of the user. Specifically, it is the input of basic information of the concert, and to customize the position and size of buttons. It is also possible that there is a difference by the user for the amount of the appropriate annotations. Such a function can adjust the amount of annotation is considered. That case, it is necessary that appropriate annotation amount is defined. Then, it is necessary to devise the algorithm to generate it.

In this paper, experiments with a focus on usability of smartphone applications were performed primarily; a brief experiment was performed for the user experience of the whole system. As a future work, it is necessary to evaluate the user experience by increasing the subject.

\section{References}

1. Niconico douga (February 2014), http://www.nicovideo.jp/

2. Hamano, S., Azuma, H., Kitada, A. (eds.): Niconico douga no seiseiryoku. NHK Publishing (2008) (Japanese)

3. Buxton, B.: Sketching User Experiences: Getting the Design Right and the Right Design. Morgan Kaufmann (2007)

4. Yamaoka, T.: The Design of GUI. Designproject, No.90 24(2), 40-43 (2011)

5. Yamaoka, T.: Human technology design Introduction, pp. 69-70. Morikita Publishing (2003)

6. Yamaoka, T.: Human technology design Introduction, pp.75-76. Morikita Publishing (2003)

7. (HANS) Kemp, J.A.M., Gelderen, T.V.: Co-discovery exploration: an informal method for the interactive design of consumer products. In: Usability Evaluation in Industry, pp. 139-146. Taylor and Francis (1996)

8. Yamaoka, T.: Proposed Methods for Extracting and Analyzing User Requirements by Usability Task Analysis. JSSD 56(6), 37-46 (2010)

9. Bradley, M.M., Peter, J.: Lang: Measuring emotion: The self-assessment manikin and the semantic differential. Journal of Behavior Therapy and Experimental Psychiatry 25(1), 49-59 (1994)

10. Mehrabian, A., Russell, J.A.: An approach to environmental psychology. The MIT Press (1974) 